\title{
IMPUESTO A LAS GANANCIAS SOBRE JUBILACIONES Y PENSIONES. CORSI E RECORSI DE LA JURISPRUDENCIA DE LA CoRTE SuPrema ARgentina
}

\section{Mauricio Goldfarb}

Universidad Nacional del Nordeste

estudiogoldfarb@hotmail.com

Recibido: 02/02/2021

Aceptado: 30/04/2021

\section{Resumen}

El presente artículo analiza la aplicación del impuesto a las ganancias a los haberes de jubilados y pensionados en la República Argentina. En tal sentido, se pasa revista al sistema previsional argentino y a las principales características del tributo, incluyendo también referencias a la regulación de la materia en otros países. En el objeto principal de la investigación se analizan los vaivenes del más alto tribunal argentino respecto a la constitucionalidad de gravar los haberes previsionales con el impuesto. Para ello, se examinan las principales decisiones judiciales de la Corte Suprema de Justicia de la Nación entre 2013 y 2020, con el desarrollo de los argumentos centrales expuestos por los magistrados y las partes del proceso.

Palabras clave: jubilaciones, pensiones, vulnerabilidad, tributos, impuesto a la renta.

Income Tax on Retirement. Corsi e Recorsi of the Jurisprudence of the Argentine Supreme Court

\footnotetext{
Abstract

This paper analyzes the application of income tax to the assets of retirees and pensioners in the Argentine Republic. In this sense, its take review the Argentine pension system and the main characteristics of the income tax, including references to the regulation in other countries. In the main object of the investigation, the ups and downs of the highest Argentine court regarding the constitutionality of taxing pension assets with the income tax. For this, it exposes the main judicial decisions of the Supreme Court of Justice of the Nation between
} 
2013 and 2020, with the development of the central arguments of the magistrates and the parties of the process.

Key words: retirement, pensions, vulnerability, taxes, income tax.

\section{Introducción}

A lo largo de la última década, ha existido un importante debate en la República Argentina respecto a la constitucionalidad de la aplicación del impuesto a las ganancias sobre los haberes jubilatorios. La discusión se ha visto incrementada por el cada vez mayor número de personas alcanzadas por este tributo. Este aumento en el padrón de sujetos obligados a tributar -que antes incluía a muy pocos jubilados y pensionados- obedeció a dos razones principales: en primer lugar, a que luego del piso alcanzado durante la gravísima crisis social, política y económica de 2001/2002, ${ }^{1}$ los beneficios previsionales tuvieron un fuerte incremento, tanto en términos nominales como reales. En segundo término, y especialmente a partir de 2005 , porque este aumento en los valores nominales no se vio acompañado de las necesarias actualizaciones de los mínimos no imponibles (exentos del tributo) y de las escalas tributarias. De tal modo, año tras año, más y más jubilados y pensionados pasaron a ser sujetos pasivos del impuesto, originariamente previsto para los beneficios más altos, generando un aumento de la conflictividad y la litigiosidad (Corral y Wyczykier, 2021, p. 341).

¿Es posible gravar los beneficios previsionales con el impuesto a las ganancias? ¿Existen verdaderos obstáculos constitucionales al respecto o se trata, en cambio, de una cuestión de ponderación y oportunidad, delegada al criterio de los legisladores? El propósito de este trabajo es analizar cuáles han sido las respuestas a estas cuestiones, considerando especialmente las oscilaciones jurisprudenciales del máximo tribunal de la República Argentina. El tema es relevante y de actualidad no solo por la cantidad de sujetos alcanzados por los términos de la ley tributaria vigente, sino por la acentuada litigiosidad de la materia, los distintos criterios jurisprudenciales adoptados y lo reciente de los últimos fallos de la Corte Suprema de Justicia de la Nación.

Para el desarrollo del tema, estructuramos el trabajo con el siguiente esquema: en primer lugar, una sumaria descripción de los rasgos distintivos del sistema previsional argentino y una breve revista sobre las características y evolución

1 La crisis derivó en el estallido del sistema de convertibilidad del peso argentino con el dólar estadounidense vigente durante más de una década, e incluyó la renuncia del presidente Fernando de la Rúa y la sucesión de cinco presidentes en once días, todo en medio de una gravísima convulsión social. 
del impuesto a las ganancias en nuestro país. También se incluye -a título comparativo- una breve referencia a la regulación de la materia en otros Estados de Iberoamérica para examinar alternativas posibles de solución al problema. Luego de contextualizar la cuestión en este marco teórico e histórico, desarrollamos el objeto principal de la investigación con una reseña cronológica de los principales fallos de la Corte Suprema acerca de la aplicación del impuesto a las ganancias a los haberes de jubilados y pensionados. Finalmente, planteamos algunas reflexiones e interrogantes sobre el tema, que, por otra parte, de ningún modo pretenden clausurar el debate sobre la materia.

\section{Metodología}

La presente investigación combinó procedimientos cuantitativos y cualitativos para lograr una mejor comprensión del objeto de estudio. Los datos de campo han sido extraídos de la página web oficial de la Corte Suprema de Justicia de la Nación de Argentina; ${ }^{2}$ los aspectos teóricos, consultando la bibliografía de referencia y las publicaciones más actualizadas en el tema.

La unidad de análisis estudiada comprende los fallos dictados sobre esta materia durante el período que va de diciembre de 2013 a diciembre de 2020 . Al tratarse del máximo tribunal nacional, la doctrina que emana de su jurisprudencia posee un impacto directo en todo el territorio argentino.

Aunque la unidad de análisis se circunscribe al ámbito geográfico nacional y a los procesos tramitados en la última década, las conclusiones son extensibles a otras jurisdicciones nacionales por la semejanza de los marcos normativos aplicables, especialmente en aquellos otros países que gravan los ingresos provenientes del trabajo y de los haberes de retiro.

\section{El sistema previsional argentino}

Si bien se registran antecedentes de beneficios de retiro para militares y algunos funcionarios públicos desde fines del siglo XIX, recién en 1904 se dictó la Ley 4349, la primera que estableció el descuento obligatorio a los trabajadores activos para financiar el sistema jubilatorio. La ley creó la Caja Nacional de Jubilaciones y Pensiones Civiles, a la que le siguieron, ya en la década de 1920, las cajas de jubilaciones y pensiones para los trabajadores de empresas de servicios

Disponible en: https://www.csjn.gov.ar/. 
públicos y para los empleados bancarios. En 1939 se sumaron las cajas de los trabajadores gráficos, los de la marina mercante y los de la aeronáutica civil.

Es a partir de la segunda mitad de la década de 1940 -en un movimiento no solo local, sino de escala global- que se produce el aumento y masificación de la seguridad social en la Argentina, que de cubrir a solo una pequeña porción de los trabajadores activos pasó a ser mayoritaria, cubriendo tanto a trabajadores en relación de dependencia como independientes.

El respaldo normativo del sistema previsional argentino se modificó en 1957, ${ }^{3}$ cuando la reforma de la Constitución Nacional de ese año incorporó el artículo 14bis, que, en su último párrafo establece:

\begin{abstract}
El Estado otorgará los beneficios de la seguridad social, que tendrá carácter de integral e irrenunciable. En especial, la ley establecerá: el seguro social obligatorio, que estará a cargo de entidades nacionales o provinciales con autonomía financiera y económica, administradas por los interesados con participación del Estado, sin que pueda existir superposición de aportes; jubilaciones y pensiones móviles; la protección integral de la familia; la defensa del bien de familia; la compensación económica familiar y el acceso a una vivienda digna. ${ }^{4}$
\end{abstract}

Como se advierte en la lectura del texto constitucional, existe una obligación en cabeza del Estado de proveer un sistema de seguridad social, en el que los beneficios de jubilación y pensión deben ser móviles. La movilidad reconocida constitucionalmente debe ser interpretada de modo que el monto del beneficio previsional signifique una proporción de los salarios de los trabajadores activos, en relación con los aportes realizados y de manera que, al menos, se mantenga el nivel de vida previo al cese (carácter sustitutivo de la jubilación). En palabras de la reiterada jurisprudencia de la Corte Suprema: "La jubilación constituye una consecuencia de la remuneración que percibía el beneficiario como contraprestación de su actividad laboral una vez cesada ésta y como débito de la comunidad por dicho servicio". ${ }^{5}$

Sin embargo, la movilidad y proporcionalidad jubilatorias pocas veces se

3 También debe recordarse que la Constitución de 1949 (derogada en 1956) reconocía expresamente entre los derechos del trabajador, la familia y la ancianidad al derecho a la seguridad social, entre otros derechos de segunda generación.

4 Énfasis agregado.

5 Corte Suprema de Justicia de la Nación, Berçaitz, Miguel Ángel s/Jubilación, sentencia del 13/09/1974; Maestre, Guillermo Bernardino s/Jubilación, sentencia del 21/05/1987; Sánchez, María del Carmen c/ ANSeS s/reajustes varios, del 28/07/2005; y Badaro, Adolfo Valentin c/ANSeS s/reajustes varios, del 08/08/2006, entre muchas otras sentencias. 
han cumplido en nuestro país (Gelli, 2013, p. 218). En un reciente trabajo, Justo (2021) recuerda que la garantía constitucional de la movilidad jubilatoria reconoce el derecho del titular de un beneficio a conservar una situación patrimonial proporcional a la que le correspondería de haber seguido en actividad, pero que no equivale a la intangibilidad del haber ni le impide al legislador establecer restricciones en cuanto a su monto, siempre y cuando se funden en razones de interés general y no se tornen confiscatorias.

En 1958 se dictó la Ley 14499, que estableció el haber jubilatorio como equivalente al 82\% móvil de la remuneración mensual del cargo desempeñado al momento de obtener el beneficio.

En 1968, el sistema adquirió un carácter más integral cuando se dictaron las leyes jubilatorias 18037 (para todos los trabajadores en relación de dependencia) y 18038 (para trabajadores autónomos e independientes). ${ }^{6}$ Solo subsistieron como sistemas especiales los correspondientes a las Fuerzas Armadas, jueces y personal de las administraciones públicas provinciales y municipales, que siguieron contando con sus propios organismos otorgantes y sus propias condiciones de acceso a los beneficios.

Con muchas modificaciones y complementos, las leyes 18037 y 18038 mantuvieron su vigencia hasta la crisis casi terminal del sistema, que derivó en el dictado en 1993 de la Ley 23241. ${ }^{7}$ Esta última ley creó el Sistema Integrado de Jubilaciones y Pensiones (SIJP), un sistema único (para autónomos y en relación de dependencia) de cobertura de las contingencias de vejez, invalidez y muerte.

El régimen modificó sustancialmente el sistema previsional vigente hasta entonces y significó un verdadero cambio de paradigma. En su origen, se hallaba conformado por un régimen mixto: por un lado, un sistema previsional público (financiado a través de un sistema de reparto) y de modo concurrente un régimen previsional basado en la capitalización individual, que resultaba fuertemente promocionado y que constituía el motor principal de la reforma (Corte et al., 1993).

Este sistema mixto duró hasta 2008, cuando se dictó la Ley 26425 que dispuso la unificación del Sistema Integrado de Jubilaciones y Pensiones en un único régimen previsional público y estatal denominado Sistema Integrado

6 Los textos ordenados de ambos regímenes se hallan disponibles en: http://servicios.infoleg.gob. ar/infolegInternet/anexos/25000-29999/28127/norma.htm y http://servicios.infoleg.gob.ar/infolegInternet/anexos/30000-34999/31924/norma.htm, respectivamente.

7 Texto actualizado de la norma disponible en: http://servicios.infoleg.gob.ar/infolegInternet/ anexos/0-4999/639/texact.htm. 
Previsional Argentino (SIPA). El manejo de todos los fondos pasó a un sistema solidario de reparto, otorgándoles a los afiliados y beneficiarios del régimen de capitalización vigente hasta la fecha idéntica cobertura y tratamiento que la brindada por el régimen previsional público. Así, se eliminó completamente el régimen de capitalización individual creado en el sistema anterior, que fue absorbido y sustituido por un régimen de reparto completamente público. Este sistema de reparto, además de los aportes de los empleadores, se financia con un mecanismo de solidaridad intergeneracional: los trabajadores activos aportan parte de su salario para financiar parte del pago de los beneficios de los trabajadores ya jubilados; luego, los futuros trabajadores aportarán para los que aportaron en años anteriores, y así sucesivamente.

La diferencia entre el total de los aportes efectivos y los recursos del sistema para hacer frente al pago de los beneficios son soportados por el Estado. Sin embargo, el aumento de beneficios otorgados sin la cantidad de aportes exigidos por la ley y la existencia de alrededor de un $40 \%$ de trabajadores informales que no realizan ningún tipo de aportes al sistema (Bertranou y Casanova, 2014, p. 29) actúan como una fuente de desfinanciamiento de todo el sistema. La garantía estatal de fondos públicos disponibles para garantizar el pago de las prestaciones generó un histórico, grave y permanente problema de déficit previsional, agudizado en el último lustro, en el que llegó a representar el 2,6\% del producto bruto interno (PBI) (Calcagno, 2020).

A nivel nacional, el organismo encargado de la administración de los fondos destinados al pago de los beneficios es la Administración Nacional de Seguridad Social (ANSES), un ente descentralizado creado en 1991 para tal fin, como sucesor del anterior Instituto Nacional de Previsión Social. ${ }^{8}$

Las prestaciones básicas del sistema son la jubilación y la pensión. El beneficio jubilatorio se obtiene cuando se cumplen los requisitos legales de edad (60 y 65 años, según se trate de mujeres o de hombres) y de años de aportes (normalmente 30 años); o cuando se produce una situación invalidante en el desempeño de un cargo activo o se alcanza una edad muy avanzada aun sin los aportes totales. ${ }^{9}$

El beneficio de pensión deriva de una jubilación concedida, o que le hubiera correspondido, a un trabajador activo ya fallecido. Son beneficiarios sus familiares, sucesores o convivientes más directos, en algunos casos de manera

8 Disponible en: http://servicios.infoleg.gob.ar/infolegInternet/anexos/10000-14999/12368/norma.htm.

9 Ley 24241, artículos 46 y 47. 
automática, y en otros bajo ciertas condiciones de vulnerabilidad (minoridad, discapacidad, etc.). ${ }^{10}$

Todos los beneficios previsionales establecidos por la ley son personalísimos, no pueden ser enajenados ni embargados (salvo por alimentos y litis expensas) y son imprescriptibles. ${ }^{11}$

\section{Breve historia del impuesto a las ganancias en la Argentina}

El impuesto a las ganancias nació en la República Argentina en 1932 -durante el primer Gobierno de facto surgido del golpe de Estado de septiembre de 1930con el nombre de "impuesto a los réditos". En su origen, fue presentado como un remedio extraordinario para paliar el déficit fiscal de la época, tanto, que la norma original de creación del tributo establecía que la imposición caducaba en diciembre de $1934 .{ }^{12}$ Sin embargo, sucesivas prórrogas y transformaciones lo fueron extendiendo sin solución de continuidad, tanto en el tiempo como en los hechos imponibles alcanzados. ${ }^{13}$

En 1973, la Ley 20628 modificó el régimen general, sustituyó la expresión réditos por la de ganancias y estableció la cuarta categoría de ingresos (correspondiente a los trabajadores en relación de dependencia, hasta entonces exentos del tributo). Según el texto ordenado de la ley, ${ }^{14}$ el impuesto comprende entonces cuatro categorías divididas según la fuente de las ganancias:

- Primera categoría: ganancias generadas por el usufructo de los inmuebles urbanos y rurales.

- Segunda categoría: ingresos obtenidos por acciones, intereses, dividendos y participaciones societarias.

- Tercera categoría: ganancias de las sociedades y empresas unipersonales.

- Cuarta categoría: ganancias obtenidas por el trabajo personal, sean provenientes del ejercicio de profesiones liberales o del desempeño de cargos públicos nacionales, provinciales, municipales o cualquier clase de relación de dependencia.

10 Ley 24241, artículo 53. Los requisitos particulares para los beneficios, así como los trámites necesarios para obtenerlos, pueden consultarse en: https://www.argentina.gob.ar/anses/jubilados.

11 Ley 24241, artículo 14.

12 Texto de la Ley 11856 disponible en: http://servicios.infoleg.gob.ar/infolegInternet/verNorma. do?id=293614.

13 Todavía hoy, el artículo 1 de Ley 20628 subraya el carácter transitorio del impuesto, cuando determina que: "Todas las ganancias obtenidas por personas humanas, jurídicas o demás sujetos indicados en esta ley, quedan alcanzados por el impuesto de emergencia previsto en esta norma”.

14 Disponible en: http://servicios.infoleg.gob.ar/infolegInternet/anexos/330000-334999/332890/texact.htm. 
En lo que es el objeto de nuestro estudio, el inciso c) del artículo 79 (82 en el t.o. de 2019) prevé expresamente como fuentes de ganancia, y, como tales, sujetas al impuesto, a "las jubilaciones, pensiones, retiros o subsidios de cualquier especie en cuanto tengan su origen en el trabajo personal".

La cuarta categoría fue originariamente prevista para alcanzar a salarios muy altos (cargos directivos o de conducción) tanto para trabajadores activos como jubilados. A través de la determinación de mínimos no imponibles importantes, la cantidad efectiva de sujetos alcanzados por este tributo fue históricamente muy baja.

Sin embargo, como ya hicimos notar, especialmente a partir de 2005, con el aumento de los índices inflacionarios y la falta de actualización de las escalas y montos del impuesto, esta situación comenzó a modificarse de manera sostenida, incluyendo cada vez a más jubilados y pensionados como sujetos obligados a tributar el impuesto. Y es que no actualizar en forma suficiente las bases del impuesto en períodos de alta inflación provoca un doble efecto distorsivo: que más personas queden alcanzadas y que quienes ya tributaban pasen a estar obligados con alícuotas más elevadas; en ambos casos, aun cuando sus ingresos sean iguales o menores en términos de poder adquisitivo real.

La distorsión que se experimentó fue tan notoria que, en 2013, el impuesto alcanzaba ya a casi el 30\% de los trabajadores en relación de dependencia (Basualdo, 2014), una situación que, con algunos altibajos, se mantiene a la fecha con más de un $25 \%$ del total de los empleados dependientes. Justamente, la retención directa por los propios entes encargados de pagar los salarios y jubilaciones, realizada de modo automático sobre los pagos mensuales, es una de las que mayores controversias y resistencias ha suscitado en materia tributaria (Litvin, 2011), política y social en los últimos años

Como se trata de un impuesto no solo directo (que tiene en cuenta a la persona), sino también progresivo, la incorporación o no como sujeto alcanzado no es un tema menor: las alícuotas arrancan desde el 5\% y pueden alcanzar hasta el 35\% del salario bruto. ${ }^{15}$ Esta situación ubicaba en 2013 a la Argentina como el país latinoamericano de mayor costo impositivo sobre salarios brutos, con una cuña fiscal del $34,6 \%$ del total del salario (personas solteras) y del $33 \%$ (personas casadas), según datos publicados por el la Organización para la Cooperación y el Desarrollo Económicos (OCDE) y el Banco Interamericano de Desarrollo (BID). ${ }^{16}$

15 Ley 20628, artículo 90.

16 Diponible en: https://publications.iadb.org/publications/spanish/document/Impuestos-sobre-los-salarios-en-Am\%C3\%A9rica-Latina-y-el-Caribe-Resumen.pdf. 
Además, al ser el impuesto a las ganancias un tributo de cálculo anual, las retenciones mensuales se van acumulando, no tienen un porcentaje fijo mensual y quedan sujetas a la determinación final, que surge de la declaración jurada que debe presentar el obligado, en la que puede incluir algunas deducciones (cargas de familia, un porcentaje de gastos médicos, pago de servicio de casas particulares, entre otros). ${ }^{17}$

El impuesto a las ganancias no solo es el más importante impuesto directo de la Argentina, sino que -desde hace décadas- es el segundo tributo por cantidad de recaudación, con una participación del 32\% sobre el total de la recaudación de impuestos nacionales; ${ }^{18}$ solo es superado en cantidad por el impuesto al valor agregado (IVA). ${ }^{19}$ Además, y por su complejidad, es uno de los impuestos que mayor número de normas complementarias y modificatorias ha tenido a lo largo de toda su historia. ${ }^{20}$

\section{El impuesto a la renta sobre las jubilaciones y pensiones en los sistemas tributarios de otros Estados}

¿Qué ocurre con los ingresos de jubilados y pensionados en otros países? ¿Se encuentran también alcanzados por impuestos análogos al que aquí consideramos? Si bien la descripción y el juicio de compatibilidad de cada sistema tributario nacional sobre las rentas con sus propias normas constitucionales excede largamente el marco de este trabajo, una comparación de las principales reglas de otros países de Iberoamérica resulta útil para poner en contexto y pensar posibles soluciones alternativas a la cuestión.

La importancia del tema a nivel regional es creciente, ya que, como lo destaca la doctrina, el impuesto a la renta sobre personas físicas -como se denomina en todos estos países- ha experimentado también un crecimiento como recurso fiscal en las últimas décadas. Sin embargo, este aumento no se relaciona en forma directa con una mayor tributación de las personas con ingresos más altos, sino con el crecimiento de las bases imponibles y con aumentos no de-

17 Ley 20628, artículo 23 y concordantes.

18 Este porcentaje comprende tanto la recaudación de ganancias sobre personas físicas como personas jurídicas.

19 Puede cotejarse en la serie de 1997 a 2021, disponible en: https://www.argentina.gob.ar/economia/ ingresospublicos/pormes.

20 El texto ordenado y actualizado de la ley puede consultarse en: http://servicios.infoleg.gob.ar/infolegInternet/anexos/330000-334999/332890/texact.htm. 
bidamente actualizados de los montos exentos mínimos (Rossignolo, 2015) y registra todavía muchas posibilidades de crecimiento en la cantidad de sujetos alcanzados y en la eficacia de la recaudación (Sabaini y Rossignolo, 2014, p. 98).

En Latinoamérica, de acuerdo a la información publicada en un estudio conjunto del BID, la OCDE y el Banco Mundial (BM), ${ }^{21}$ las jubilaciones y pensiones tienen un tratamiento impositivo muy diverso según el país del que se trate. Así, de los 26 países latinoamericanos incluidos en el estudio, ${ }^{22}$ en 19 no se grava la renta proveniente de jubilaciones y pensiones o se ofrecen exenciones o ventajas adicionales para las personas adultas mayores. En general, la mayoría de los sistemas impositivos otorgan un tratamiento preferencial a los ingresos de los jubilados y pensionados por sobre los que perciben los trabajadores activos. Únicamente en 7 países -entre los que se incluía a la Argentina a la fecha del informe- ${ }^{23}$ el tratamiento fiscal de las pensiones es igual que para las personas en edad de trabajar.

Este tratamiento diferenciado -más favorable- para los jubilados y pensionados ya había sido referido en el excelente trabajo comparativo de González (1997). En su investigación, el autor detalló cómo, a esa fecha, los países latinoamericanos en su mayoría o eximían completamente del pago del impuesto a la renta a las pensiones en general (México, Venezuela, Nicaragua, El Salvador, Guatemala, Paraguay, Perú, Surinam, Guyana), o establecían exenciones para algunos tipos especiales de beneficios previsionales (Barbados, Brasil, Panamá, República Dominicana, Trinidad y Tobago) o bien establecían montos no imponibles o alícuotas diferenciadas más favorables para los retirados.

Otro caso interesante es el de España. Allí, la Ley 35/2006 del Impuesto sobre la Renta de las Personas Físicas (IRPF) ${ }^{24}$ considera, al igual que en Argentina, a las jubilaciones y pensiones como ingresos que deben ser considerados a los fines del impuesto a la renta. Así lo establece expresamente el artículo 17.2.a. de la norma, que abarca a "las pensiones y haberes pasivos percibidos de

21 Disponible en: https://publications.iadb.org/publications/spanish/document/Panorama-de-las-Pensiones-Am\%C3\%A9rica-Latina-y-el-Caribe.pdf.

22 Argentina, Bahamas, Barbados, Belice, Bolivia, Brasil, Chile, Colombia, Costa Rica, Ecuador, El Salvador, Guatemala, Guyana, Haití, Honduras, Jamaica, México, Nicaragua, Panamá, Paraguay, Perú, República Dominicana, Surinam, Trinidad y Tobago, Uruguay y Venezuela.

23 En la actualidad, esta situación es distinta en nuestro país, donde se establecen algunas deducciones especiales a favor de los jubilados y pensionados según el texto vigente desde 2019. La última reforma -Ley 27617, sancionada en abril de 2021- también incluye algunas leves mejoras para el caso de los trabajadores jubilados en relación con los activos, como veremos más adelante.

24 Texto íntegro disponible en: https://www.boe.es/buscar/act.php?id=BOE-A-2006-20764. 
los regímenes públicos de la Seguridad Social y clases pasivas y demás prestaciones públicas por situaciones de incapacidad, jubilación, accidente, enfermedad, viudedad, o similares".

De todos modos, como actualmente el mínimo no imponible -siempre que no se tengan ingresos de otra fuente- es de 22000 euros anuales (artículo 96 de la Ley 35/2006) y la pensión media en España asciende a 14500 euros anuales, se calcula que, a la fecha, 7 de cada 10 pensionados españoles no pagan el impuesto a la renta. ${ }^{25}$

Sin embargo -y esto es muy trascendente en el marco de esta investigación, como se verá más adelante-, la ley española establece en su artículo 7 importantes casos de exención al impuesto, discriminando supuestos en atención a la especial situación de vulnerabilidad de quien lo recibe. Así, se encuentran también exentos del impuesto a la renta

las prestaciones reconocidas al contribuyente por la Seguridad Social o por las entidades que la sustituyan como consecuencia de incapacidad permanente absoluta o gran invalidez [artículo 7, inciso f]; Las pensiones por inutilidad o incapacidad permanente del régimen de clases pasivas, siempre que la lesión o enfermedad que hubiera sido causa de aquéllas inhabilitara por completo al perceptor de la pensión para toda profesión u oficio [artículo 7, inciso g].

\section{Igualmente están exentas}

las ayudas económicas otorgadas por instituciones públicas a personas con discapacidad con un grado de minusvalía igual o superior al 65 por ciento o mayores de 65 años para financiar su estancia en residencias o centros de día, siempre que el resto de sus rentas no excedan del doble del indicador público de renta de efectos múltiples [artículo 7 , inciso i]. ${ }^{26}$

Por último, la ley española contiene otra nota a favor de sujetos especialmente vulnerables, al permitir reducciones especiales del monto a tributar por aportaciones y contribuciones a los sistemas de previsión social constituidos a favor de personas con discapacidad (artículo 53).

25 Disponible en: https://www.tuproyectodevida.es/irpf-pensiones-jubilacion/.

26 También se encuentran exentos otros supuestos, como las pensiones derivadas de actos de terrorismo, de la guerra civil española o por privación ilegítima de la libertad, entre otras situaciones ya menos frecuentes (artículo 7 de la Ley de IRPF). 


\section{Resultados de la investigación}

A continuación, pasaremos revista a la evolución de la jurisprudencia de la Corte Suprema de Justicia de la Nación sobre la aplicación del impuesto a las ganancias a los haberes previsionales desde 2013 hasta 2020. Al considerar estas sentencias, también se incluyen referencias - por su relevancia- a los fundamentos de los fallos de las cámaras federales como instancia inferior a la Corte.

\subsection{La jurisprudencia de los tribunales inferiores a la Corte Suprema hasta 2013}

Como referimos más arriba, el proceso inflacionario y la falta de actualización de los mínimos no imponibles generó un incremento muy significativo de la cantidad de personas alcanzadas por el impuesto. El hecho de gravar a más personas con este tributo -que, además, percibían sumas que lejos estaban de ser exorbitantes- produjo un brusco aumento de los cuestionamientos a la constitucionalidad y a la razonabilidad del impuesto.

De acuerdo a la estructura judicial de la República Argentina, ${ }^{27}$ los procesos de impugnación de la constitucionalidad se iniciaron ante los juzgados federales de primera instancia de todo el país. Un número cada vez más importante de jubilados y pensionados obtuvo medidas cautelares y sentencias favorables, muchas de las cuales incluso fueron confirmadas por las cámaras federales de apelaciones, todo ello con gran trascendencia en los medios especializados y los de alcance general.

La inmensa mayoría de estos procesos -iniciados entre 2005 y 2013- tramitó bajo la forma de amparo, la vía más expedita y sencilla prevista para la tutela de derechos constitucionales afectados por actos u omisiones manifiestamente arbitrarios o ilegales, tanto del poder público como de particulares. ${ }^{28}$

\subsection{Dejeanne (2013)}

El 10 de diciembre de 2013, la Corte Suprema de Justicia de la Nación resolvió el caso Dejeanne, Oscar Alfredo y otro c/Administración Federal de Ingresos Públicos (AFIP) s/amparo. Se trataba de una causa en la que el actor había impugnado la

27 Artículos 116 y siguientes de la Constitución Nacional.

28 Constitución Nacional, artículo 43: "Toda persona puede interponer acción expedita y rápida de amparo, siempre que no exista otro medio judicial más idóneo, contra todo acto u omisión de autoridades públicas o de particulares, que en forma actual o inminente lesione, restrinja, altere o amenace, con arbitrariedad o ilegalidad manifiesta, derechos y garantías reconocidos por esta Cons- 
constitucionalidad del impuesto a las ganancias sobre sus haberes jubilatorios. En primera instancia, el Juzgado Federal $\mathrm{N}^{\circ} 1$ de Corrientes dictó sentencia rechazando la acción, con el argumento de que no existía ilegalidad o arbitrariedad manifiesta.

Apelada la decisión por el actor, la Cámara Federal de Corrientes hizo lugar al recurso y declaró la inconstitucionalidad del artículo 79 inciso c) de la Ley 20628, en cuanto alcanzaba con el impuesto a las ganancias a los haberes jubilatorios del actor, por ser violatorio de los artículos 16, 17 y 18 de la Constitución Nacional. ${ }^{29}$

Al analizar la vía utilizada para impugnar la constitucionalidad, la Cámara Federal consideró que el amparo era idóneo, en virtud de que la cuestión era de puro derecho y que no exigía mayor debate y prueba. Además, y en relación con el fondo de la cuestión, la Cámara sostuvo que los haberes jubilatorios "no son una ganancia" ni el fruto de una actividad humana (el hecho imponible previsto en la ley), sino una prestación que constituye "el pago de un débito que la sociedad tiene con el jubilado, no pasible de tributo alguno debido a su carácter alimentario".

Llegada la causa a su conocimiento, la Corte Suprema de Justicia hizo lugar al recurso extraordinario federal interpuesto por la demandada AFIP y revocó la sentencia, para así rechazar el amparo. El fallo se compone de un voto conjunto que conforma la mayoría, suscripto por los doctores Highton de Nolasco, Maqueda, Zaffaroni y Fayt y un voto en disidencia de la doctora Argibay. La mayoría sostuvo:

Que la cuestión relativa a la vía del amparo planteada por la recurrente ha sido adecuadamente tratada en el dictamen de la señora Procuradora Fiscal, cuyos

titución, un tratado o una ley. En el caso, el juez podrá declarar la inconstitucionalidad de la norma en que se funde el acto u omisión lesiva.

Podrán interponer esta acción contra cualquier forma de discriminación y en lo relativo a los derechos que protegen al ambiente, a la competencia, al usuario y al consumidor, así como a los derechos de incidencia colectiva en general, el afectado, el defensor del pueblo y las asociaciones que propendan a esos fines, registradas conforme a la ley, la que determinará los requisitos y formas de su organización.

Toda persona podrá interponer esta acción para tomar conocimiento de los datos a ella referidos y de su finalidad, que consten en registros o bancos de datos públicos, o los privados destinados a proveer informes, y en caso de falsedad o discriminación, para exigir la supresión, rectificación, confidencialidad o actualización de aquéllos. No podrá afectarse el secreto de las fuentes de información periodística.

Cuando el derecho lesionado, restringido, alterado o amenazado fuera la libertad física, o en caso de agravamiento ilegítimo en la forma o condiciones de detención, o en el de desaparición forzada de personas, la acción de hábeas corpus podrá ser interpuesta por el afectado o por cualquiera en su favor y el juez resolverá de inmediato, aun durante la vigencia del estado de sitio".

29 Sentencia del 27/09/10. 
fundamentos son compartidos por el Tribunal y a los que corresponde remitir en razón de brevedad.

En su dictamen -al que el fallo remitió-, la procuradora Dra. Laura Monti subrayó que el actor no había acreditado la supuesta confiscatoriedad del impuesto y que, al menos en el limitado examen de una acción de amparo -un proceso constitucional de naturaleza excepcional-, no se evidenciaba ni la arbitrariedad ni la ilegalidad manifiesta de las retenciones. La procuradora sostuvo también que la ley era muy clara en el sentido de considerar a las jubilaciones como una fuente de renta gravada, lo cual, por tratarse de atribuciones que la Constitución Nacional ponía en cabeza del Congreso de la Nación, excluía el supuesto de ilegalidad manifiesta. Además, a diferencia de lo que sostuvo la Cámara Federal, la procuradora entendió que la discusión acerca de la constitucionalidad o no del tributo exigía un mayor debate y prueba, excediendo el acotado margen del amparo. ${ }^{30}$

Con este fallo, la Corte Suprema fijó claramente el criterio de que la vía del amparo no era apta para cuestionar la legitimidad del impuesto a las ganancias a los jubilados y pensionados. Al mismo tiempo, y aun cuando omitió expedirse sobre el fondo de la cuestión, emitió una clara señal favorable a la validez constitucional del impuesto sobre los haberes previsionales. En especial, por la circunstancia muy conocida de que la inmensa mayoría de los cuestionamientos había utilizado la acción de amparo como vía procesal.

\subsection{Acciones de amparo falladas con posterioridad (2014/2015)}

A tenor de lo resuelto por la Corte Federal en Dejeanne, la mayoría de los juzgados federales de primera instancia y las cámaras federales de apelación adaptaron su criterio al del máximo tribunal, aun cuando muchos de ellos solo lo hicieron por razones de economía procesal.

Como consecuencia de ello, los reclamos de los jubilados empezaron a ser desestimados, con el argumento de que la acotada vía del amparo no era idónea para discutir la constitucionalidad del tributo. A pesar de ello, muchos expedientes siguieron llegando a la Corte por la vía del recurso extraordinario, especialmente en aquellos casos cuyo trámite se hallaba ya muy avanzado. El tribunal supremo se ocupó de estos recursos. En algunos casos, con una mera

30 El dictamen completo de la doctora Laura Monti puede consultarse en: https://www.mpf.gov.ar/ Dictamenes/2011/LMonti/octubre/Dejeanne_Oscar_D_248_L_XLVII.pdf. 
remisión a Dejeanne (16 sentencias en total; 11 en 2014, 5 en 2015 para resolver un total de 104 acciones de amparo rechazadas). ${ }^{31}$ En muchos otros casos, el tribunal acudió directamente a la vía del certiorari (artículo 280 del Código Procesal Civil y Comercial) para desestimar el recurso extraordinario interpuesto por los actores y así confirmar los fallos de instancias anteriores. ${ }^{32}$

\subsection{García (2019)}

Los términos del rechazo de la acción en la causa Dejeanne, al estar referidos exclusivamente a la vía procesal de impugnación, dejaron subsistente la discusión de fondo: ¿es constitucional la aplicación del impuesto a las ganancias a los haberes previsionales? Y si así fuera, ¿lo es en todos los casos o deben considerarse las circunstancias particulares de la persona involucrada?

La controversia se vio reforzada por un desajuste entre los índices inflacio-

31 Corte Suprema de Justicia de la Nación, Cadenas, Miguel c/Administración Federal de Ingresos Públicos (A.F.I.P.) s/amparo; Cáceres, Juan Rito c/Administración Federal de Ingresos Públicos (A.F.I.P.) s/ amparo; Carbone, Antonio c/Administración Federal de Ingresos Públicos (AFIP) -suc. Corrientes-s/amparo, todos del 01/04/14; Carnevale, Carlos Horacio c/Adm. Federal de Ingresos Públicos (AFIP) suc. Corrientes s/amparo, del 5/08/14; Encina, Alberto c/AFIP s/amparo, del 09/09/14; Boichuk, Margarita Gladys c/AFIP s/amparo, del 30/09/14; Bacigalupi, Maria Esther c/AFIP s/amparo y Chauveaux, Julia Esther c/A.F.I.P. s/amparo ley 16986, ambas del 14/10/14; Cantadori, Delia María c/AFIP s/amparo ley 16986, del 28/10/14; Gramajo, Rosa Sara c/A.F.I.P. s/Amparo Ley 16.986, del 19/02/15; Berrastro, Carolina c/Afip s/Amparo, del 13/05/15; Añasco, Nicolas Taciano c/Administración Federal de Ingresos Públicos (A.F.I.P.) - Suc. Ctes. s/Amparo, del 4/05/2015; Santiago Delia Beatriz c/Afip - Dgi s/Amparo Ley 16.986, del 14/04/2015; y Lagomarsino Pinedo, Alicia Angélica c/Afip s/Amparo Ley 16.986, del 7/04/2015. Disponibles en: https://sjconsulta.csjn.gov.ar/sjconsulta/documentos/verUnicoDocumentoLink.html?idAnalisis=710037\&cache=1619132726616; https://sjconsulta.csjn.gov.ar/ sjconsulta/documentos/verUnicoDocumentoLink.html?idAnalisis=711450\& cache $=1619132849519$; https://sjconsulta.csjn.gov.ar/sjconsulta/documentos/verUnicoDocumentoLink.html?idAnalisis=715574\& cache=1619132923650; https://sjconsulta.csjn.gov.ar/sjconsulta/documentos/verUnicoDocumentoLink.html?idAnalisis=719016\& cache=1619133022017; https://sjconsulta.csjn.gov.ar/ sjconsulta/documentos/verUnicoDocumentoLink.html?idAnalisis=721087\& cache=1619133095768; https://sjconsulta.csjn.gov.ar/sjconsulta/documentos/verUnicoDocumentoLink.html?idAnalisis $=720563 \&$ cache $=1619133214593$.

32 Y ello sin necesidad de expresar las razones del rechazo. Así lo autoriza de manera explícita el Código Procesal Civil y Comercial de la Nación luego de la reforma de la Ley 23774 (1990): "Artículo 280. Llamamiento de autos. Rechazo del recurso extraordinario. Memoriales en el recurso ordinario. Cuando la Corte Suprema conociere por recurso extraordinario, la recepción de la causa implicará el llamamiento de autos. La Corte, según su sana discreción, y con la sola invocación de esta norma, podrá rechazar el recurso extraordinario, por falta de agravio federal suficiente o cuando las cuestiones planteadas resultaren insustanciales o carentes de trascendencia” (el destacado me pertenece).

Aunque excede el objeto de este trabajo e importantes sectores de la doctrina han defendido el instituto del certiorari, no podemos dejar de señalar que la subsistencia de la potestad de la Corte Suprema de rechazar un recurso extraordinario sin dar razón alguna no parece compatible con el sistema republicano ni con el derecho a obtener una decisión fundada. 
narios y la falta o el ínfimo ajuste del mínimo que -nuevamente- provocó un ascenso en el número de personas alcanzadas por el impuesto: de casi 62000 jubilados que pagaban el tributo en 2015 se pasó a más de 163000 en 2019 (Universidad Nacional de Avellaneda, 2021, p. 9).

Como el agua que busca su cauce, muchas de las pretensiones de los jubilados y pensionados se volcaron a otras vías procesales distintas del amparo: las acciones declarativas de inconstitucionalidad ${ }^{33}$ o los juicios contenciosos ordinarios. Y, nuevamente, los tribunales inferiores comenzaron a dictar medidas cautelares y sentencias favorables a los actores, ya sin que se pudiera cuestionar la vía utilizada para la impugnación (argumento a contrario de Dejeanne).

Finalmente, uno de estas causas arribó por la vía del recurso extraordinario federal y fue resuelta por el máximo tribunal nacional. En marzo de 2019, la jurisprudencia de la Corte Suprema de Justicia tuvo una modificación trascendente con el dictado de la sentencia en Garcia, Maria Isabel c/Administración Federal de Ingresos Públicos s/acción declarativa de inconstitucionalidad. ${ }^{34}$ En su fallo, el tribunal confirmó la resolución de la Cámara Federal de Paraná que declaró la inconstitucionalidad del artículo 79 inciso c) de la Ley 20628 de Impuesto a las Ganancias. La Cámara Federal había ordenado a la demandada reintegrarle a la actora - una jubilada de 79 años de edad que había trabajado como diputada y docente y sufría de varios problemas de salud- los montos que se le habían retenido por aplicación de la normativa descalificada en términos constitucionales. El argumento principal de la sentencia de Cámara era que "la jubilación no es una ganancia”, sino un débito que la sociedad posee para con quien realizó aportes durante su vida laboral. ${ }^{35}$

La sentencia de la Corte Suprema se compone de un voto común de la mayoría, integrada por los doctores Lorenzetti, Maqueda, Highton de Nolasco y Rosatti. ${ }^{36}$ Los fundamentos más importantes del fallo se exponen a partir del

33 Este tipo de acciones se encuentran previstas en el artículo 322 del Código Procesal Civil y Comercial de la Nación: "Artículo 322. Podrá deducirse la acción que tienda a obtener una sentencia meramente declarativa, para hacer cesar un estado de incertidumbre sobre la existencia, alcance o modalidades de una relación jurídica, siempre que esa falta de certeza pudiera producir un perjuicio o lesión actual al actor y éste no dispusiera de otro medio legal para ponerle término inmediatamente".

34 El fallo completo se halla disponible en: https://sjconsulta.csjn.gov.ar/sjconsulta/documentos/verDocumentoByIdLinksJSP.html?idDocumento=7511573\& cache $=1565361026977$.

35 Se trata del mismo argumento que sostuvo la Cámara Federal de Corrientes en la ya referida causa Dejeanne.

36 El doctor Carlos Rozenkrantz votó en disidencia. El presidente de la Corte auspició el rechazo de la demanda en un extenso voto, en el que comparte y amplía la fundamentación del dictamen de la procuradora Laura Monti en la causa Cuesta, Jorge Antonio c/AFIP s/acción de inconstitucionalidad, 
considerando $8^{\circ}$ del voto de la mayoría. Allí, el tribunal se pregunta a sí mismo si todos los jubilados y pensionados se encuentran en las mismas circunstancias -como para recibir un tratamiento fiscal igualitario- o si existen condiciones especiales, basadas en un estado de mayor vulnerabilidad (producto de la avanzada edad u otras situaciones particulares como la discapacidad, que justifiquen un tratamiento diferenciado). La respuesta es negativa y constituye el fundamento central de la decisión.

El voto de la mayoría recuerda que la garantía de igualdad ante la ley radica en consagrar un trato legal igualitario a quienes se hallan en una razonable igualdad de circunstancias y:

\begin{abstract}
Que, en materia impositiva, el principio de igualdad no solo exige la creación de categorías tributarias razonables (Fallos: 150:189; 160:247) sino que también prohíbe la posibilidad de unificar las consecuencias tributarias para situaciones que en la realidad son distintas (Fallos: 149:417; 154:337; 156:352; 195:270; 184:592; $209: 431 ; 210: 322 ; 234: 568)$. En efecto, desde el punto de vista constitucional, hacer prevalecer el principio de igualdad supone reconocer que es tan injusto gravar en distinta forma a quienes tienen iguales medios como imponer la misma contribución a quienes están en desigual situación. (Considerando $10^{\circ}$ )
\end{abstract}

Profundizando el análisis de este principio, el voto mayoritario destacó la diferencia entre la igualdad formal del artículo 16 de la redacción originaria de la Constitución Nacional respecto a la igualdad real de oportunidades promovida por el artículo 75 inciso 23 de la reforma de 1994, que ordena al Congreso de la Nación: "Legislar y promover medidas de acción positiva que garanticen la igualdad real de oportunidades y de trato, y el pleno goce y ejercicio de los derechos reconocidos por esta Constitución y por los tratados internacionales vigentes sobre derechos humanos".

Y es que el reconocimiento de la necesidad de tutela diferenciada a los grupos históricamente más vulnerables implica, según el alto tribunal, un imperativo constitucional que:

Resulta transversal a todo el ordenamiento jurídico, proyectándose concretamente a la materia tributaria, ya que no es dable postular que el Estado actúe con una mirada humanista en ámbitos carentes de contenido económico inmediato (libertades de expresión, ambulatoria o tránsito, etc.) y sea insensible al momento de definir su política fiscal. Es que, en definitiva, el sistema tributa-

también fallado el 26/03/2019. 
rio no puede desentenderse del resto del ordenamiento jurídico y operar como un compartimento estanco, destinado a ser autosuficiente "a cualquier precio", pues ello lo dejaría al margen de las mandas constitucionales. (Considerando $15^{\circ}$ in fine)

En su sentencia, la Corte Suprema no deja de recordar el tradicional estándar cuantitativo de la confiscatoriedad, utilizado históricamente para invalidar tributos por la afectación al derecho de propiedad, pero subraya que el principio:

\begin{abstract}
Resulta insuficiente si no se pondera la vulnerabilidad vital del colectivo concernido. La falta de consideración de esta circunstancia como pauta de diferenciación tributaria supone igualar a los vulnerables con quienes no lo son, desconociendo la incidencia económica que la carga fiscal genera en la formulación del presupuesto de gastos que la fragilidad irroga, colocando al colectivo considerado en una situación de notoria e injusta desventaja. En esas condiciones el estándar de revisión judicial históricamente adoptado por esta Corte, según el cual los términos cuantitativos de la pretensión fiscal solo deben ser invalidados en caso de confiscación, no permite dar una adecuada respuesta a la protección constitucional de contribuyentes como los anteriormente descriptos. (Considerando $17^{\circ}$ )
\end{abstract}

Por todo ello, el voto de la mayoría concluyó que la consideración legislativa del universo de contribuyentes (jubilados y pensionados) como un todo homogéneo responde a un modelo constitucional de corte previo a la reforma de 1994, pero actualmente incompatible con el texto de la Constitución Nacional. Este diseño legal, que no toma razón de que se trata de un colectivo heterogéneo en razón de los distintos grados de vulnerabilidad de sus integrantes, ha devenido por ello inconstitucional (considerando $18^{\circ}$ ). Para dejar clara su postura, los ministros que conforman la mayoría aclararon que tampoco se pretendía establecer, a los efectos del pago del impuesto, cuál debe ser la capacidad "de cada jubilado concreto", pues ello equivaldría a "consagrar la insensatez de promover tantas categorías como beneficiarios existan en el sistema" (considerando $20^{\circ}$ del voto de la mayoría).

Es importante subrayar que el fallo de la Corte, aun cuando concluye en la eximición del impuesto a la reclamante, no abre juicio respecto al razonamiento de la instancia anterior (los beneficios previsionales no son ganancias) al que soslaya, fundando su decisorio exclusivamente en la falta de diferenciación en el universo de jubilados y pensionados.

La sentencia incluye también -obiter dictum- una reflexión sobre la causa 
probable de esta falta de subcategorizaciones dentro del colectivo de jubilados y pensionados, así como una posible manera en la que el Estado puede salvarla con los medios tecnológicos que tiene hoy a su alcance:

Es probable que la falta de percepción fina respecto de la subcategorización de los jubilados, incorporando los elementos relevantes de la vulnerabilidad a la capacidad económica inicial, se explique por la reiteración de un standard patrimonial escogido varias décadas atrás en las que era tecnológicamente imposible distinguir -dentro del universo rotulado como "jubilados"- entre quienes son vulnerables en mayor o menor medida. Hoy esta diferenciación puede extraerse -cuanto menos en sus trazos más notorios, que es lo que busca el legislador- a partir de la propia información registral en poder del Estado. Bastaría con cruzar los datos de los departamentos previsionales y asistenciales estatales competentes para generar sub clasificaciones que conformaran estándares impregnados de justicia y simplificaran la tarea revisora de los tribunales. (Considerando $19^{\circ}$ )

Por último, el fallo contiene una exhortación al Congreso de la Nación a que realice las modificaciones legislativas que brinden un tratamiento diferenciado para aquellos "beneficiarios en situación de mayor vulnerabilidad que se encuentran afectados por el tributo, en especial los más ancianos, enfermos y discapacitados" (considerando $23^{\circ}$ ).

\subsection{Otras acciones declarativas de certeza (2019)}

El precedente García tuvo un impacto tan profundo que si bien no tuvo efectos erga omnes por las características del sistema judicial argentino, se proyectó al universo de todas las prestaciones jubilatorias que tengan su origen en el trabajo personal (Spisso, 2019, p. 13).

La Corte simplemente remitió a lo resuelto en García para confirmar un número importante de sentencias de instancias inferiores, que también habían declarado la inconstitucionalidad del tributo. Así, durante 2019/2020 dictó 19 fallos en las que se resolvió con la mera remisión al precedente. ${ }^{37}$ En 12 de ellos

37 Corte Suprema de Justicia de la Nación, Godoy, Ramón Esteban c/AFIP s/Acción meramente declarativa de Inconstitucionalidad, del 28/05/2019; Montefiori, Sonia Haydée c/AFIP s/Acción meramente declarativa de Inconstitucionalidad, del 25/06/2019; Chichizola, Norberto Hernán c/AFIP s/Acción meramente declarativa de Inconstitucionalidad, del 02/07/2019; Mazzola de Marsico, Ana María c/AFIP s/Acción meramente declarativa de inconstitucionalidad, también del 02/07/2019; Piccoli, Alfredo Victorio c/AFIP s/Acción meramente declarativa de Inconstitucionalidad y otros, del 16/07/2019; Recurso de hecho deducido por la demandada en la causa Federik, Emma Stella Maris c/AFIP s/acción meramente declarativa de inconstitucionalidad, del 29/08/2019; Fornari, Silvia Cristina y otros c/Poder Ejecutivo Nacional y otros s/acción meramente declarativa 
se trataba de sentencias múltiples, en las que se resolvían varias causas a la vez (de 3 y hasta 32 expedientes en una misma resolución).

Utilizando este procedimiento, con las 17 sentencias que remitieron a García se resolvieron 176 expedientes, todos ellos, casos que tramitaban como acciones meramente declarativas. Además, se dictaron otros 2 fallos en causas tramitadas como de conocimiento (contencioso administrativo), en las que también se utilizó la remisión a García para acoger el planteo de los actores. ${ }^{38}$

Sin embargo, y esto es muy relevante a tenor de los pronunciamientos que consideraremos a posteriori, la Corte Suprema dejó de incluir (especialmente en las sentencias que abarcaban más de un expediente o varios actores) referencias a las especiales situaciones de discapacidad, edad muy avanzada o de salud que pudieran afectar a los demandantes.

\subsection{Los expedientes sobre reajustes de haberes contra la Administración Nacional de Seguridad Social (2020)}

Es un hecho muy conocido que el sistema previsional argentino posee un alto grado de litigiosidad. ${ }^{39}$ Con acierto, Gelli (2013, p. 221) señala que ello obedece a dos falencias estructurales del sistema previsional: la concesión arbitraria de beneficios a quienes nunca aportaron al sistema -con el consiguiente desfinanciamiento- y la nivelación hacia abajo de las retribuciones a quienes sí aportaron. Y es que todo sistema previsional requiere un equilibrio entre los aportantes y los beneficiarios: a menor proporción de aportantes sobre beneficiarios, es evidente que el porcentaje de aporte deberá ser mayor, o los beneficios disminuidos o generarse un déficit crónico del sistema. Lamentablemente, nuestra experiencia histórica demuestra que todos estos efectos negativos han ocurrido sucesiva o simultáneamente.

En ese contexto, el viraje hacia un mayor reconocimiento de la invalidez del tributo fue parcialmente confirmado -al menos de un modo tácito- por otras seis sentencias de la Corte Suprema dictadas durante 2020. Estos fallos

de inconstitucionalidad, también del 29/08/2019; Villegas, Raquel Nora y otros c/Administración Federal de Ingresos Públicos s/acción meramente declarativa de derecho, del 17/09/2019; entre otras.

38 Corte Suprema de Justicia de la Nación, Castro, Beatriz Marina c/EN - AFIP s/Proceso de conocimiento; Rodriguez, Eladio Antonio c/EN - AFIP s/ Proceso de Conocimiento; Ordóñez Graciela Mabel c/AFIP - DGI s/contencioso administrativo, todos del 02/07/2019.

39 Véase el llamado de la Corte a evitar los planteos jurisdiccionales evitables, en un reciente fallo, referido a la ejecución de deudas contra el Estado nacional: Martinez, Gabriel Rubén c/Estado Nacional Ministerio del Interior Policía Federal Argentina s/ daños y perjuicios, del 03/12/2020. 
se referían -en todos estos casos- a la aplicación del impuesto a las ganancias sobre los retroactivos reconocidos a jubilados por juicios contra la ANSES por el incorrecto pago de sus haberes. ${ }^{40}$

Al ratificar las decisiones de la Cámara Federal de la Seguridad Social sobre la improcedencia de la retención del impuesto, la Corte Suprema extendió de hecho los efectos de García, al menos de un modo tácito.

Basta recordar que, en varios de los fallos confirmados, la Cámara Federal de la Seguridad Social sostuvo que:

No corresponde afectar impositivamente el saldo retroactivo percibido en concepto de diferencias por prestaciones previsionales mal abonadas. Ello así, pues ninguna duda cabe que la percepción de las acreencias de esta naturaleza no puede constituir nunca un hecho imponible, y menos todavía ser pasibles de gravamen alguno, sin colocar en serio riesgo el principio de integridad del que gozan las prestaciones previsionales.

\subsection{Rodas, Ferreyra y Frette, ¿el regreso del amparo? (diciembre de 2020)}

La confirmación definitiva del cambio de rumbo del máximo tribunal tuvo lugar el 17 de diciembre de 2020. Ese día, la Corte Suprema dictó tres sentencias en juicios tramitados como acciones de amparo, ${ }^{41}$ en las cuales remitió a lo resuelto en García. Casualmente, y al igual que en Dejeanne, se trataba de procesos de amparo tramitados ante la Justicia Federal de la provincia de Corrientes. En todos estos casos, la Cámara Federal de Corrientes había rechazado la demanda por estricta aplicación de la doctrina emanada de la Corte Suprema sobre la improcedencia de la vía del amparo (Dejeanne, de 2013).

40 Corte Suprema de Justicia de la Nación, Datorre, Manuel Víctor c/ANSeS s/reajustes varios; García, Marta Susana c/ANSeS s reajustes varios, ambos del 10/09/20; Villamayor, Homero Jorge c/ANSeS s/ reajustes varios, del 17/09/20; Bonatti, Carlos Alberto c/ANSeS s/reajustes varios, del 08/10/20; Bayón, Maria c/ANSES y otros s/Reajustes y otros, del 03/12/2020; Moreno, José Manuel c/ANSES s/reajustes varios, del 10/12/2020; entre otras causas.

41 Corte Suprema de Justicia de la Nación, Rodas, Jorge Ernesto c/AFIP s/amparo ley 16.986; Albornoz, Maria Teresa c/AFIP s/amparo ley 16.986; Ali, Rosa Teresita c/Administración Federal de Ingresos Públicos s/amparo ley 16.986; Chamorro, Eduardo Alberto c/AFIP s/amparo ley 16.986; Ferreyra, Fermín Casto c/Administración Federal de Ingresos Públicos s/amparo ley 16.986; D’Amico, Agustín Bibiano c/Administración Federal de Ingresos Públicos s/amparo ley 16.986; Frette, Roberto Antonio c/AFIP s/amparo ley 16.986; todos resueltos el 17/12/2020. Las sentencias completas se hallan disponibles en: http://sjconsulta.csjn.gov.ar/sjconsulta/documentos/verUnicoDocumentoLink.html?idAnalisis=763157\&cache=1612016605909; http://sjconsulta.csjn.gov.ar/sjconsulta/documentos/verUnicoDocumentoLink.html?idAnalisis=763159\& cache=1612016594479; http: $/$ sjconsulta.csjn.gov.ar $/$ sjconsulta $/$ documentos/verUnicoDocumentoLink.html?idAnalisis=763154\& cache $=1612016578508$. 
En los tres casos resueltos en 2020, y dejando de lado el precedente de 2013 sobre la improcedencia de la vía del amparo, la Corte Suprema hizo lugar a los recursos extraordinarios de los actores, con el fundamento de: "Que las cuestiones planteadas por la recurrente encuentran adecuada respuesta en el precedente de esta Corte 'García, Maria Isabel' (Fallos: 342:411), cuyos fundamentos y conclusiones, en lo pertinente, se dan por reproducidos por razón de brevedad”.

De esta manera, el máximo tribunal abandonó el criterio de la improcedencia de la vía del amparo para cuestionar la constitucionalidad del impuesto a las ganancias. Las razones para un cambio de criterio tan radical -sin perjuicio de los antecedentes que detallamos en el apartado 6.6.- solo pueden deducirse de los considerandos de García, ya que en los fallos de diciembre de 2020 solo se hace una remisión a dicho precedente. La respuesta más plausible puede encontrarse en la afirmación de una inconstitucionalidad evidente del tributo subrayada en García por la no consideración de las distintas categorías de vulnerabilidad que pueden afectar a los jubilados y pensionados. ${ }^{42}$ Así, la norma que establece la aplicación del impuesto sobre los haberes de jubilados y pensionados devendría manifiestamente inconstitucional por ser incompatible con el mandato de protección preferencial del artículo 75 inciso 23, por afectar el principio de igualdad en sentido amplio (al tratar del mismo modo a situaciones desiguales) y como consecuencia de ello irrazonable (y contraria al principio del artículo 28 de la Constitución Nacional).

Pero esta conclusión deja sin una respuesta coherente a la cuestión del momento en el que "la tipología originaria del legislador, carente de matices" se convirtió en "una manifestación estatal incoherente e irrazonable, violatoria de la Constitución Nacional” (considerando $18^{\circ}$ de García). Si la inconstitucionalidad sobreviniente tuvo lugar a partir de la sanción de la reforma de 1994, la postura no se compadece con la propia jurisprudencia de la Corte Federal, en especial con lo resuelto en Dejeanne.

Estas consideraciones no aparecen abordadas -ni de modo expreso ni de modo tácito- en ninguno de los fallos dictados en 2020. En el mismo sentido, no parece una cuestión menor que en el dictamen de la procuradora en Dejeanne (que la Corte hizo suyo) no solo se sostuvo la improcedencia del amparo por inexistencia de arbitrariedad o ilegalidad manifiesta, sino que además se subrayó la plena potestad constitucional del Congreso de la Nación de imponer tributos y, en especial referencia a la procedencia de la vía del amparo, la necesidad un mayor debate y prueba para discutir la eventual confiscatoriedad. 
Por ello, hubiera sido mucho más conveniente que la Corte Suprema hiciera explícitas las razones del cambio jurisprudencial, sobre todo considerando que varios de los ministros del tribunal (Highton y Maqueda) suscribieron tanto los fallos que rechazaban como los que admitían la procedencia del amparo sin que parecieran advertir contradicción alguna en sostener un cambio de 180 grados en la solución jurídica. Además, no puede soslayarse el hecho de que, en muchos de los casos a los que se amplió la solución de García (por ejemplo, los que sostuvieron la inaplicabilidad del impuesto a los retroactivos reconocidos judicialmente), no se hicieron referencias -ni siquiera mínimas- a situaciones de salud o de alguna otra condición especial de vulnerabilidad, lo que no permite determinar una línea de fundamentación clara del máximo tribunal para la impugnación constitucional del tributo.

\section{Conclusiones}

De la revisión incluida en los apartados anteriores resulta claro que la cuestión de la constitucionalidad de la aplicación del impuesto a las ganancias a los ingresos provenientes de jubilaciones y pensiones es no solo un tema altamente controvertido, sino que ha merecido respuestas jurisdiccionales muy distintas a lo largo de los últimos años. Se trata de una cuestión especialmente sensible no solo por el colectivo afectado (integrado por muchos sujetos especialmente vulnerables), sino también porque se traduce en la intersección de distintos subsistemas jurídicos -el derecho tributario, el de la seguridad social y el de la ancianidad- que postulan principios y soluciones muy diferentes para un mismo problema (Soria, 2020). Es evidente que encontrar el punto de equilibrio entre el interés público por dotar de más recursos al Fisco y el interés individual de un beneficio jubilatorio más justo y digno será siempre conflictivo, cualquiera sea la solución que se adopte desde el punto de vista legislativo o fiscal.

Hemos visto también que el argumento principal de la Corte en García -ahora aplicado a los procesos de amparo- fue la falta de diferenciación entre los distintos grados de vulnerabilidad que pueden presentar los integrantes de esa categoría tributaria. Así, la conducta estatal de cobrar el tributo a todos los jubilados y pensionados por igual devendría incoherente e irrazonable y, como tal, violatoria de la Constitución Nacional (Carnota, 2019). Por estas razones, parece claro que mientras subsista el déficit legislativo de diferenciación en el heterogéneo colectivo de los jubilados y pensionados indicado por la Corte Suprema, la inconstitucionalidad seguiría siendo palmaria. 
En este sentido, la última reforma a la Ley 20628, sancionada el 8 de abril de 2021 bajo el número de Ley 27617 y actualmente vigente con efecto retroactivo al 1 de enero, tampoco se hace cargo del vicio señalado por la Corte, ya que no incorpora distinciones basadas en la mayor o menor vulnerabilidad de la persona. En la única referencia diferenciada a favor de los beneficios previsionales, el artículo 7 de la ley aumentó la suma no imponible, que pasó de 6 a 8 veces del total de los haberes mínimos jubilatorios garantizados. ${ }^{43}$ Este incremento del mínimo no imponible hace que, en los hechos, todos los jubilados y pensionados que perciben hasta $\$ 164000$ de ingresos mensuales $-y$ que no tengan otros ingresos- dejen de estar alcanzados por el impuesto, excluyendo así aproximadamente al $80 \%$ de los que venían sufriendo retenciones (Universidad Nacional de Avellaneda, 2021).

Sin embargo, cabe preguntarse qué ocurriría si el Congreso de la Nación estableciera nuevas y diversas categorías o, de algún otro modo, diferenciara especialmente las situaciones de mayor o menor vulnerabilidad de los jubilados y pensionados, como hemos visto que sucede en otros países (por ejemplo, en España). En este sentido, es importante tener en cuenta que la Corte Suprema no ha adherido - al menos hasta la fecha- al criterio sostenido de manera constante por varias de las Cámaras Federales (de la Seguridad Social, de Corrientes, de Paraná, entre otras) respecto a la inconstitucionalidad de raíz y ab initio del impuesto.

Esta cuestión puede advertirse con claridad en el propio fallo García, en el que la Corte incluyó una referencia a los fundamentos de la Cámara Federal de Paraná. En su sentencia, la Cámara -como muchos otros tribunales inferiores a la Corte- sostuvo la inconstitucionalidad del impuesto a las ganancias sobre los haberes jubilatorios por la afectación de la integralidad del haber y por la doble imposición que resultaría de gravar la actividad laboral y luego el beneficio previsional. En este razonamiento, la Cámara Federal admitió en todas sus partes la pretensión del actor, y en sus considerandos sostuvo que:

La jubilación no es una ganancia, sino un débito que tiene la sociedad con el jubilado que le permite gozar de un beneficio cuando la capacidad laborativa disminuye o desaparece y que por lo tanto no es pasible de ningún tipo de imposición tributaria posterior.

43 Ley publicada en el Boletín Oficial de la República Argentina del 21/04/21. Texto completo de la norma disponible en: https://www.boletinoficial.gob.ar/detalleAviso/primera/243262/20210421. 
Del cotejo de las estas dos líneas argumentativas -aun cuando ambas concluyan declarando la inconstitucionalidad del tributo- resulta claro que es muy distinto sostener que "la jubilación no es ganancia" (como lo hacen las cámaras federales y otros tribunales inferiores) que afirmar que el tributo deviene irrazonable, solo por no diferenciar las distintas condiciones de vulnerabilidad dentro del conjunto heterogéneo de los jubilados y pensionados (como lo sostiene la mayoría de la Corte).

Sin perjuicio de la posibilidad -siempre válida- de un cambio de la jurisprudencia, el derecho a una decisión fundada, como derivación de la tutela judicial efectiva, y especialmente cuando emana del máximo tribunal judicial de la nación y resuelve sobre temas de tanta trascendencia social, requiere que se expliquen con toda claridad las razones de una mudanza de criterio tan importante, como el que resulta de comparar Dejeanne (2013) con los casos Rodas, Ferreyra y Frette (2020).

Es evidente que no solo los jubilados y pensionados, sino también toda la sociedad, se merecen una respuesta clara y coherente de parte del Poder Judicial y del resto de los poderes públicos respecto a esta cuestión, que ha merecido respuestas tan disímiles en el breve lapso de siete años en fallos que incluso llevan, en varios casos, la firma de los mismos jueces (Nieto, 2019). Elementales razones de orden y seguridad jurídica así lo exigen.

El debate parece lejos de estar cerrado, como resulta de la discusión y sanción de una nueva ley de reforma del impuesto en 2021. Seguramente, con el dictado de nuevos fallos de la Corte Suprema y de los tribunales inferiores, y con las previsibles modificaciones normativas a los que nos tiene acostumbrado este tributo en particular, asistiremos a nuevos capítulos de esta ya larga discusión sobre la constitucionalidad de este impuesto y su aplicación a los haberes previsionales.

\section{Bibliografía}

Basualdo, E. (Coord.). (2014). Impuesto a las ganancias cuarta categoría. Centro de Investigación y Formación de la República Argentina. http://www.centrocifra.org.ar/docs/IC\%20 Nro\%2016\%20\%28segundo\%20adelanto\%29.pdf.

Bertranou, F. y Casanova, L. (2014). Informalidad laboral en Argentina. Segmentos críticos y políticas para la formalización. Oficina de País de la OIT para Argentina. https://www.ilo.org/wcmsp5/groups/public/@americas/@ro-lima/@ilo-buenos_aires/documents/publication/ wcms_248462.pdf. 
Calcagno, L. (2020). La sustentabilidad de la seguridad social argentina: cómo medir el déficit de la ANSES (1993-2019). Realidad Económica, 49(333), 39-62. https://ojs.iade.org.ar/ index.php/re/article/view/113.

Carnota, W. (2019). Hacia una jurisprudencia de la vulnerabilidad: cuando los jubilados no pagan impuesto a las ganancias (En el centenario de la Constitución de Weimar de 1919). Revista Derechos de las Minorias, (1), 30-39.

Corral, D. y Wyczykier, G. (2021). La politización de la cuarta categoría. El conflicto en torno al Impuesto a las ganancias en la Argentina (2012-2016). Trabajo y Sociedad, XXII(36), 333-360.

Corte, N., De Virgilis, M. y Tabernero, R. (1993). Nuevo sistema previsional argentino. Rubinzal Culzoni.

Gelli, M. (2013). Constitución de la Nación Argentina, comentada y concordada (Tomo I). La Ley.

González, D. (1997). Estudio Comparado del Impuesto sobre la Renta de los Países Miembros del CIAT. Centro Interamericano de Administraciones Tributarias.

Justo, J. (2021). La movilidad jubilatoria en la jurisprudencia de la Corte Federal argentina. Principios generales. Diario Administrativo, (312). https://dpicuantico.com/area_diario/ doctrina-en-dos-paginas-diario-administrativo-nro-312-04-03-2021/.

Litvin, C. (2011). Impuesto a las Ganancias. La Ley.

Nieto, M. (2019). La Corte Federal y el Poder Impositivo. Un nuevo caso: Los ingresos por jubilación ¿son renta gravada? ¿quién lo dice? ¿cuáles son los límites? DECONOMI, II(1), 80-99.

Organización de Cooperación y Desarrollo Económicos, Banco Interamericano de Desarrollo y Banco Mundial. (2015). Panorama de las pensiones: América Latina y el Caribe. https://publications.iadb.org/es/panorama-de-las-pensiones-america-latina-y-el-caribe.

Organización de Cooperación y Desarrollo Económicos, Centro Interamericano de Administraciones Tributarias y Banco Interamericano de Desarrollo. (2016). Impuestos sobre los salarios en América Latina y el Caribe. https://www.oecd-ilibrary.org/taxation/taxing-wagesin-latin-america-and-the-caribbean-2016_9789264262607-en.

Rossignolo, D. (2015). El Impuesto sobre la Renta Personal y los altos ingresos en América Latina. Hacienda Pública Española / Review of Public Economics, (214), 115-148.

Sabaini, J. y Rossignolo, D (2014). La tributación sobre las altas rentas en América Latina. Naciones Unidas/CEPAL. https://www.cepal.org/es/publicaciones/35896-la-tributacion-altas-rentas-america-latina.

Soria, G. (2020). El caso "García contra AFIP”: La transversalidad del Derecho de la Ancianidad. Revista Cartapacio de Derecho, 37.

Spisso, R. (2019). Inconstitucionalidad del impuesto a las ganancias sobre prestaciones jubilatorias. Control abstracto de constitucionalidad. La Ley.

Universidad Nacional de Avellaneda. (2021). Haberes Jubilatorios. Informe. Observatorio de Políticas Públicas. https://www.undav.edu.ar/general/recursos/adjuntos/28830.pdf.

\section{Jurisprudencia citada}

\section{Corte Suprema de Justicia de la Nación}

Albornoz, María Teresa c/AFIP s/amparo ley 16986, 17/12/2020.

Alí, Rosa Teresita c/Administración Federal de Ingresos Públicos s/amparo ley 16986, 17/12/2020. 
Añasco, Nicolás Taciano c/Administración Federal de Ingresos Públicos (A.F.I.P.) - Suc. Ctes. s/Amparo, 04/05/2015.

Bacigalupi, Maria Esther c/AFIP s/amparo, 14/10/2014.

Badaro, Adolfo Valentín c/ANSeS s/reajustes varios, 08/08/2006.

Bayón, Maria c/ANSES y otros s/Reajustes y otros, 03/12/2020

Berçaitz, Miguel Ángel s/Jubilación, 13/09/1974.

Berrastro, Carolina c/Afip s/Amparo, 13/05/2015.

Boichuk, Margarita Gladys c/AFIP s/amparo, 30/09/2014.

Bonatti, Carlos Alberto c/ANSeS s/reajustes varios, 08/10/2020.

Cáceres, Juan Rito c/Administración Federal de Ingresos Públicos (A.F.I.P.) s/amparo, 01/04/2014.

Cadenas, Miguel c/Administración Federal de Ingresos Públicos (A.F.I.P.) s/amparo, 01/04/2014.

Cantadori, Maria c/AFIP s/amparo ley 16986, 28/10/2014.

Carbone, Antonio c/Administración Federal de Ingresos Públicos (AFIP) suc. Corrientes-s/amparo, 01/04/2014

Carnevale, Carlos Horacio c/Adm. Federal de Ingresos Públicos (AFIP) suc. Corrientes s/amparo, 05/08/2014.

Castro, Beatriz Marina c/EN - AFIP s/Proceso de conocimiento, 02/07/2019.

Chamorro, Eduardo Alberto c/AFIP s/amparo ley 16986, 17/12/2020.

Chauveaux, Julia Esther c/A.F.I.P. s/amparo ley 16986, 14/10/2014.

Chichizola, Norberto Hernán c/AFIP s/Acción Meramente Declarativa de Inconstitucionalidad, 02/07/2019.

Cuesta, Jorge Antonio c/AFIP s/acción de inconstitucionalidad, 26/03/2019.

D'Amico, Agustin Bibiano c/Administración Federal de Ingresos Públicos s/amparo ley 16986, $17 / 12 / 2020$.

Datorre, Manuel Victor c/ANSeS s/reajustes varios, 10/09/2020.

Dejeanne, Oscar Alfredo y otro c/Administración Federal de Ingresos Públicos (AFIP) s/amparo, $10 / 12 / 2013$.

Encina, Alberto c/AFIP s/amparo, 09/09/2014.

Ferreyra, Fermin Casto c/Administración Federal de Ingresos Públicos s/amparo ley 16986, 17/12/2020.

Fornari, Silvia Cristina y otros c/Poder Ejecutivo Nacional s/acción meramente declarativa de inconstitucionalidad, 29/08/2019.

Frette, Roberto Antonio c/AFIP s/amparo ley 16986, 17/12/2020.

García, Maria Isabel contra Administración Federal de Ingresos Públicos s/acción declarativa de inconstitucionalidad, 26/03/2019.

García, Marta Susana c/ANSeS s/reajustes varios, 10/09/2020.

Godoy, Ramón Esteban c/AFIP s/Acción Meramente Declarativa de Inconstitucionalidad, 28/05/2019.

Gramajo, Rosa Sara c/AFIP s/Amparo Ley 16986, 19/02/2015.

Lagomarsino Pinedo, Alicia Angélica c/Afip s/Amparo Ley 16986, 07/04/2015.

Maestre, Guillermo Bernardino s/Jubilación, 21/05/1987.

Martinez, Gabriel Rubén c/Estado Nacional Ministerio del Interior Policía Federal Argentina s/daños y perjuicios, 03/12/2020.

Mazzola de Marsico, Ana Maria c/AFIP s/acción meramente declarativa de inconstitucionalidad, 02/07/2019. 
Montefiori, Sonia Haydée c/AFIP s/Acción meramente declarativa de Inconstitucionalidad, 25/06/2019.

Moreno, José Manuel c/ANSES s/reajustes varios, 10/12/2020.

Ordóñez Graciela Mabel c/AFIP - DGI s/contencioso administrativo, 02/07/2019.

Piccoli, Alfredo Victorio c/AFIP s/Acción meramente declarativa de Inconstitucionalidad, 16/07/2019.

Recurso de hecho deducido por la demandada en la causa Federik, Emma Stella Maris c/AFIP s/Acción meramente declarativa de Inconstitucionalidad, 29/08/2019.

Rodas, Jorge Ernesto c/AFIP s/amparo ley 16986, 17/12/2020.

Rodríguez, Eladio Antonio c/EN - AFIP s/Proceso de conocimiento, 02/07/2019.

Sánchez, Maria del Carmen c/ANSeS s/reajustes varios, 28/07/2005.

Santiago, Beatriz c/Afip - DGI s/Amparo Ley 16986, 14/04/2015.

Villamayor, Homero Jorge c/ANSeS s/reajustes varios, 17/09/2020.

Villegas, Raquel Nora c/Administración Federal de Ingresos Públicos s/acción meramente declarativa de derecho, 17/09/2019. 